\title{
Acute systemic lupus erythematosus with fatal pneumonitis and disseminated intravascular coagulation
}

\author{
MIRIAM CHELLINGSWORTH AND DAVID G I SCOTT \\ From the Department of Rheumatology, Queen Elizabeth Hospital, Edgbaston, Birmingham B15 2TJ
}

SUMMARY We report the case of a 40-year-old female with acute onset of systemic lupus erythematosus, followed rapidly by the development of fatal pneumonitis and disseminated intravascular coagulation. The likely relationship between these events and the therapeutic options are discussed.

Key words: fibrosing alveolitis, pneumonitis, systemic lupus erythematosus, overlap syndromes, disseminated intravascular coagulation.

Acute pneumonitis is a rare complication of systemic lupus erythematosus (SLE). It may be a presenting feature of the disease and carries a poor prognosis. ${ }^{1}$ Minor coagulation abnormalities are common in SLE, but severe disseminated intravascular coagulation (DIC) has rarely been reported.

We report a patient who died of acute lupus pneumonitis complicated by DIC. The likely relationship between these two events and the therapeutic options for such a problem are discussed.

\section{Case history}

A 40-year-old Indian woman presented in 1982 with a six-week history of symmetrical polyarthritis involving proximal interphalangeal joints, wrists, elbows, knees, and toes. She had a 3-year history of Raynaud's phenomenon but no history of alopecia, sun sensitivity, oral ulceration, serositis, renal, or central nervous system disease. Treatment included a variety of non-steroidal anti-inflammatory drugs.

Accepted for publication 10 July 1984.

Correspondence to Dr D G I Scott, Department of Rheumatology, Queen Elizabeth Hospital, Edgbaston, Birmingham B15 2TJ.
Investigations showed haemoglobin $11.6 \mathrm{~g} / \mathrm{dl}$, leucocytes $4.9 \times 10^{9} / 1$ (lymphocytes $0.54 \times 10^{9} / 1$ ), ESR $34 \mathrm{~mm} / \mathrm{h}$; Rose-Waaler negative, antinuclear factor positive (titre $1 / 1600$-speckled) precipitating antibody to $\mathrm{nRNP}$ positive; C3 $1.24 \mathrm{~g} / \mathrm{l}$ (normal); C4 $0 \cdot 11 \mathrm{~g} / 1$ (low). Renal function tests and $x$-rays (including chest $x$-ray) were normal.

Five weeks later she was admitted as an emergency with a five-day history of increasing dyspnoea and a dry cough, unresponsive to amoxycillin. There was no history of recent foreign travel, exposure to dust, birds, or paraquat. On examination she was dyspnoeic at rest, cyanosed, pyrexial $\left(38 \cdot 2^{\circ} \mathrm{C}\right)$, and had a tachycardia $(110 / \mathrm{min})$. Widespread inspiratory crackles were noted in both long fields, especially in the middle and lower zones. Chest $x$-ray showed bilateral mid zone alveolar mottling. Arterial blood gases while breathing air: $\mathrm{Po}_{2} 5.05$ $\mathrm{kPa}, \mathrm{PCO}_{2} 3.11 \mathrm{kPa}$. She was treated with oxygen and erythromycin with little initial improvement. Further investigations included fibreoptic bronchoscopy, which was normal, but alveolar washings and transbronchial lung biopsy showed changes consistent with desquamative interstitial pneumonitis (increased neutrophils in alveolar lavage and increased desquamation of macrophages into the alveolar spaces). There was no evidence of infection or of 
Table 1 Serial data showing the development of DIC. Coagulation tests

\begin{tabular}{|c|c|c|c|c|c|c|}
\hline $\begin{array}{l}\text { Day after } \\
\text { admission }\end{array}$ & $\begin{array}{l}\text { Prothrombin } \\
\text { ratio }(n=1.0)\end{array}$ & $\begin{array}{l}\text { Partial } \\
\text { thromboplastin } \\
\text { time }(n=41 \mathrm{~s})\end{array}$ & $\begin{array}{l}\text { Thrombin } \\
\text { time } \\
(n=16 \mathrm{~s})\end{array}$ & $\begin{array}{l}\text { Fibrinogen } \\
(n=1 \cdot 5-4 \cdot 0 \mathrm{~g} / \mathrm{l})\end{array}$ & $\begin{array}{l}\text { Fibrin degradation } \\
\text { products } \\
(n<10 \mathrm{mg} / \mathrm{l})\end{array}$ & $\begin{array}{l}\text { Platelets } \\
\left(n=150-400 \times 10^{9} / 1\right)\end{array}$ \\
\hline 5 & $1 \cdot 1$ & 38 & ND & ND & ND & 313 \\
\hline 7 & $1 \cdot 2$ & 49 & 20 & 1.42 & 115 & 124 \\
\hline 10 & $1 \cdot 3$ & 45 & 19 & 1.05 & 140 & 95 \\
\hline 11 & 1.4 & 64 & 36 & 0.57 & 240 & 24 \\
\hline
\end{tabular}

$\mathrm{ND}=$ test not done.

interstitial fibrosis. Treatment was begun with hydrocortisone $200 \mathrm{mg} 4$ times daily.

Twenty-four hours after admission she was still severely hypoxic and dyspnoeic and was therefore electively intubated and ventilated. To obtain a satisfactory arterial oxygen pressure she required an inspired oxygen concentration of $70 \%$ and positive end-expiratory pressure (PEEP) of $8 \mathrm{~cm}$ of water. The steroid dosage was changed to $40 \mathrm{mg}$ prednisolone twice daily with bolus doses of $1 \mathrm{~g}$ methylprednisolone on days 3,4 , and 7 after admission. Despite this her lung function did not alter significantly. During this period coagulation tests were performed serially and the results are shown in Table 1. On day 7 a diagnosis of DIC was made and fresh frozen plasma infusions were given on days 8 and 9. At no stage was there any clinical evidence of haemorrhage. Frequent examinations of trachial aspirate, urine, faeces, and blood failed to show any evidence of infection.

During this time her lung disease assessed clinically and by serial blood gas estimations and $x$-rays remained static. Cyclophosphamide was given as a single dose of $500 \mathrm{mg}$ and was associated with some improvement in lung function such that PEEP was discontinued. However, by day 11 her $\mathrm{PaO}_{2}$ fell and there was further deterioration in coagulation. Despite further treatment with fresh frozen plasma her condition deteriorated and on day 12 she was noted to have fixed dilated pupils. An electroencephalogram showed no activity, and tests of brain stem function were negative. These were repeated after 24 hours and ventilation was discontinued.

\section{POST - MORTEM FINDINGS}

At necropsy there was evidence of a haemorrhagic tendency with petechiae on pleural surfaces and subendocardially, and blood stained pleural and pericardial effusions. Thromboses were widespread, visible to the naked eye in the superior vena cava and pelvic veins, and on microscopy in small vessels in the myocardium, lungs, kidney, spleen, brain, and bone marrow. Several organs contained infarcts, including the myocardium, kidney, an영 spleen. The brain was diffusely swollen and almost entirely necrotic. There was no evidence off glomerulonephritis, but immunofluorescence of $\vec{a}$ frozen section showed glomerular deposition of $\mathrm{IgG}, \mathrm{A}, \mathrm{M}$, and $\mathrm{C} 3$.

The lungs were consolidated and showed a mix ture of fairly acute changes, with vascular thrond boses and intra-alveolar haemorrhage and rathe older changes. There was fibrous thickening fo alveolar walls and polypoid intra-alveolar projec. tions with hyperplastic granular pneumocytes and few giant cells. There were no granulomas, rheumatoid nodules, or significant inflammatory infiltrate and there was no evidence of arteritis Immunofluorescence of a frozen section showed periarterial deposition of immunoglobulin and con plement.

These necropsy findings are consistent with the diagnoses of systemic lupus erythematosus, fibro ing alveolitis (of fairly recent onset), and widespread disseminated intravascular coagulation.

\section{Discussion}

A diagnosis of SLE was made before our patient: terminal illness on the basis of non-deforming polyarthritis, Raynaud's phenomenon, strongR positive antinuclear factor, lymphopenia, and hype complementaemia. Although DNA antibodies wete negative and precipitating antibodies to nRN positive, our patient had no features of othep connective tissue disease (scleroderma, polymyositis) to suggest an overlap syndrome, and none of the typical finger changes seen in mixed connective tissue disease (MCTD). ${ }^{2}$ Antibodies to nRNP a no longer considered diagnostic of MCTD, and are found in many connective tissue diseases, the conw monest being SLE. ${ }^{3}$

Acute interstitial pneumonitis was diagnosed i our patient by bronchoalveolar lavage and trane bronchial biopsy. Infection and other causes of pneumonitis were excluded by the history, hist $\vec{\delta}$ logy, persistently negative sputum cultures, cytod 
ogy, and failure to respond to cessation of all anti-inflammatory drugs or addition of corticosteroids. Acute interstitial pneumonitis is a rare complication of SLE, the largest series reporting 12 patients, six of whom died. ${ }^{3}$ Pneumonitis occurs more frequently in MCTD, but is usually responsive to corticosteroids. More severe cases, unresponsive to steroids, sometimes have pulmonary vasculitis, which was not present in our case. ${ }^{+}$

Disseminated intravascular coagulation was diagnosed in our patient on the basis of thrombocytopenia, prolonged prothrombin time, partial thromboplastin time and thrombin time, low fibrinogen, and the presence of fibrin degradation products. In addition our patient had widespread thrombosis at necropsy. Severe DIC is rare in $\mathrm{SLE}^{5}{ }^{6}$ and has not been reported in MCTD. There has been recent interest in the role of the lupus anticoagulant in thrombosis in SLE. ${ }^{7}$ We did not specifically look for this in our patient's short illness, and it is possible that it played a part in the widespread thrombosis found post mortem. It is interesting that the renal histology and immunofluorescence were similar to those in the series of SLE patients with lupus anticoagulant described by Kant et al. ${ }^{\circ}$

DIC may be a primary cause of lung disease manifest as the adult respiratory distress syndrome. ${ }^{9}$ In our patient coagulation tests were normal at the onset of her illness, suggesting that DIC was a secondary event. DIC may also cause deterioration of lung function in severely ill patients by means of thrombosis in small pulmonary vessels, and it is likely that this was a major factor in our patient.

Effective therapy of acute pneumonitis in connective tissue diseases is not established. In a series of patients with interstitial pneumonitis survival depended on the initial degree of dyspnoea, age, cellular histology, and early response to steroid. ${ }^{10}$ The presence of a connective tissue disease did not affect the outcome. There are also occasional reports of benefit from azathioprine, cyclophosphamide, and penicillamine. ${ }^{11} 12$ Our clinical impression was that cyclophosphamide was beneficial for a short time and in similar cases a trial of cyclophos- phamide in higher doses and earlier in the illness may be indicated.

This patient represents the most severe end of the connective tissue disease spectrum. It is important to realise that despite the absence of renal disease and the presence of nRNP (previously associated with a good prognosis) severe and fatal problems such as acute lupus pneumonitis and DIC can occur.

We are grateful to Professors O Wade and P A Bacon for their permission to report this case. to Dr A J Howie for the report on the necropsy, and to Professor K W Walton for the report on the immunofluorescence.

\section{References}

1 Matthay R. Schwarz M. Petty T, et al. Pulmonary manifestations of SLE. Review of 12 cases of acute lupus pneumonitis. Medicine (Baltimore) 1974: 54: 397-409.

2 Sharp G. Irvin W S. Tan E. Gould R. Holman H. Mixed connective tissue disease-an apparently distinct rheumatic disease syndrome associated with a specific antibody to ENA. Am J Med 1972: 52: 148-9.

3 Field-Munves E. Schur P M. Antibodies to SM and RNPprognosticators of disease involvernent. Arthritis Rheum 1983; 26: 848-53.

4 Weiner-Kronish J P. Solinger A M. Warrock M L. Churg A. Ordonez N, Golden J A. Severe pulmonary involvement in mixed connective tissue discase. Am Rev Resp Dis 1981; 124: 499-503.

5 Beall C L. Pierce L E. Intravascular coagulation in acute lupus erythematosis. JAMA 1975; 234: 518-9.

6 McKay D G. Diseases of hypersensitivity-disseminated intravascular coagulation. Arch Intern Med 1965: 116: 83-94.

7 Boey M L. Colaco C B. Gharaui A E, Elkon K O, Loizous S. Hughes G R V. Thrombosis in systemic lupus erythematosus, striking association with the presence of circulating lupus anticoagulant. $B r$ Med $J$ 1980; 287: 1021-3.

8 Kant K S. Polla R V E. Weiss M A. Guieck H I. Miller H A. Hess E V. Glomerular thrombosis in SLE: prevalence and significance. Medicine (Baltimore) 1980; 60: 71-86.

9 Bone R. Francis P B. Pierce A. Intravascular coagulation associated with adult respiratory distress syndrome. Am J Med 1976; 61: 585-9.

10 Turner-Warwick M. Burrows B. Johnson A. Cryptogenic fibrosing alveolitis: response to corticosteroid therapy and its effect on survival. Thorax 1980; 35: 593-9.

11 Weese W C. Levine B W. Kazemi M. Interstitial lung disease resistant to corticosteroid therapy. Report of 3 cases treated with azathioprine or cyclophosphamide. Chest 1975; 67: 57-60.

12 Winterbauer R H. Hammar S P. Hallman K O. et al. Diffuse interstitial pneumonitis. Clinicopathological correlations in 20 patients treated with prednisolone/azathioprine. Am J Med 1978: 65: 661-72. 